Canadian

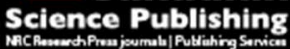

Applied Physiology, Nutrition, and Metabolism Physiologie appliquée, nutrition et métabolisme

\title{
Low and Moderate Doses of Caffeine Late in Exercise Improve Performance in Trained Cyclists
}

\begin{tabular}{|r|l|}
\hline Journal: & Applied Physiology, Nutrition, and Metabolism \\
\hline Manuscript ID & apnm-2016-0053.R2 \\
\hline Manuscript Type: & Article \\
\hline Date Submitted by the Author: & 25 -Mar-2016 \\
\hline Complete List of Authors: & $\begin{array}{l}\text { Talanian, Jason; Fitchburg State University, Exercise and Sports Science } \\
\text { Department } \\
\text { Spriet, Lawrence; University of Guelph, Department of Human Health and } \\
\text { Nutritional Sciences }\end{array}$ \\
\hline Keyword: & $\begin{array}{l}\text { ergogenic aids < nutrition, metabolism, cycling < sports, time trial, } \\
\text { exercise }\end{array}$ \\
\hline
\end{tabular}


Low and Moderate Doses of Caffeine Late in Exercise Improve Performance in Trained

\section{Cyclists}

Jason L. Talanian ${ }^{1} \&$ Lawrence L. Spriet ${ }^{2}$

${ }^{1}$ Exercise and Sports Science Department, Fitchburg State University, Fitchburg, Massachusetts, USA 01420.jtalania@fitchburgstate.edu

${ }^{2}$ Department of Human Health and Nutritional Sciences, University of Guelph, Guelph, Ontario, Canada N1G 2W1. 1spriet@uoguelph.ca

Corresponding Author: Jason L. Talanian

160 Pearl Street, EXSS Department, Fitchburg, MA, USA, 01420

Phone: 978-665-3396

Fax: 978-665-4588

Email: jtalania@fitchburgstate.edu 


\begin{abstract}
The aim of the present study was to assess if low and moderate doses of caffeine delivered in a carbohydrate-electrolyte solution (CES) late in exercise improved time trial (TT) performance. Fifteen $(11$ male, 4 female $)$ cyclists $\left(22.5 \pm 0.9 \mathrm{yr} ; 69.3 \pm 2.6 \mathrm{~kg} ; \mathrm{VO}_{2}\right.$ peak, $64.6 \pm$ $\left.1.9 \mathrm{ml} \cdot \mathrm{min}^{-1} \cdot \mathrm{kg}^{-1}\right)$ completed four double-blinded randomized trials. Subjects completed 120 min of cycling at $\sim 60 \% \mathrm{VO}_{2}$ peak with five interspersed $120 \mathrm{~s}$ intervals at $\sim 82 \% \mathrm{VO}_{2}$ peak, immediately followed by $40 \mathrm{~s}$ intervals at $50 \mathrm{~W}$. Following $80 \mathrm{~min}$ of cycling, subjects either ingested a $6 \%$ CES (PL), a CES with $100 \mathrm{mg}$ (low dose, $1.5 \pm 0.1 \mathrm{mg} \cdot \mathrm{kg} \mathrm{bm}^{-1}$ ) of caffeine (CAF1) or a CES with $200 \mathrm{mg}$ (moderate dose, $2.9 \pm 0.1 \mathrm{mg} \cdot \mathrm{kg} \mathrm{bm}^{-1}$ ) of caffeine (CAF2). Following the 120 min cycling challenge, cyclists completed a $6 \mathrm{~kJ} \cdot \mathrm{kg} \mathrm{bm}{ }^{-1} \mathrm{TT}$. There was no difference between respiratory, heart rate, glucose, free fatty acid, body weight, hematocrit or USG measurements between treatments. The CAF2 (26:36 \pm 0:22 min:sec) TT was completed faster than CAF1 $(27: 36 \pm 0: 32$ min:sec, $\mathrm{p}<0.05)$ and both CAF TT's were completed faster than PL (28:41 $\pm 0: 38$ min:sec, $\mathrm{p}<0.05)$. Blood lactate was similar between trials and rose to a greater extent during the TT $(\mathrm{p}<0.05)$. In summary, both doses of caffeine delivered late in exercise improved TT performance over the PL trial and the moderate dose (CAF2) improved performance to a greater extent than the low dose (CAF1).
\end{abstract}

Key words: ergogenic aid, metabolism, cycling, time trial, exercise, elite 


\section{Introduction}

Caffeine acts as a stimulant and its value as an ergogenic aid has been embraced by many athletes within the endurance sports community (Desbrow and Leveritt 2006; Burke 2008). The literature strongly indicates that supplementation with moderate $\left(\sim 3-6 \mathrm{mg} \cdot \mathrm{kg}\right.$ body mass $\left.(\mathrm{bm})^{-1}\right)$ and high doses $\left(>6 \mathrm{mg} \cdot \mathrm{kg} \mathrm{bm}^{-1}\right)$ of caffeine can decrease markers of fatigue and improve moderate to high intensity endurance performance (Graham 2001; Doherty and Smith 2004; Burke 2008). However even with its added popularity many athletes lack a scientific approach to using it as an ergogenic aid (Desbrow and Leveritt 2007).

Determining a minimal dose to induce optimal results may limit possible negative effects from chronic caffeine use. Negative effects are not well understood but may include addictive properties (Fredholm et al. 1999), headaches, anxiety and depression (Gilliland and Bullock 1983; Salinero et al. 2014). In addition, cessation from caffeine use may cause symptoms of withdrawal (Silverman et al. 1992), impaired performance and improved sleep (James 1998).

There are limited studies for comparison between low $\left(<2.5 \mathrm{mg} \cdot \mathrm{kg} \mathrm{bm}^{-1}\right)$ and moderate doses of caffeine on endurance performance (Table 1) (Kovacs et al. 1998; Cox et al. 2002; Jenkins et al. 2008; Desbrow et al. 2009), but there is evidence suggesting a treatment effects between doses. Kovacs et al. (1998) had cyclists ingest an initial dose of caffeine $\sim 60$ min prior to a cycling time trial (TT) and gave two further doses during the TT. Total caffeine intake was either $2.1,3.4$ or $4.5 \mathrm{mg} \cdot \mathrm{kg} \mathrm{bm}^{-1}$. All treatments improved TT performance compared to a placebo, but performances improved to a greater extent with the moderate doses $(3.4$ and $4.5 \mathrm{mg}$ $\left.\cdot \mathrm{kg} \mathrm{bm}^{-1}\right)$ compared to the low dose $\left(2.1 \mathrm{mg} \cdot \mathrm{kg} \mathrm{bm}^{-1}\right)$. 
In contrast, other studies have not observed differences in endurance performance between low and moderate concentrations of caffeine (Cox et al. 2002; Jenkins et al. 2008; Desbrow et al. 2009). However the initial dose of caffeine in these studies were ingested upwards of 80 to $180 \mathrm{~min}$ before beginning performance trials (Table 1). When the initial dose has been given closer to the performance trials ( $\sim 60$ min prior), many studies observed improvements with low and moderate doses of caffeine (Ivy et al. 1979; Wiles et al. 1992; Bridge and Jones 2006; Jenkins et al. 2008; Scott et al. 2015). Identifying significant differences between low and moderate doses of caffeine may require an initial ingestion of caffeine close to the performance trial to maximize ergogenic benefits.

Often differences observed between caffeine treatments on endurance performance are small and hard to detect statistically. Investigators need to utilize a stringent and reproducible exercise protocol that can detect these small differences in performance within a laboratory setting. As a result of these concise requirements, investigators often field complaints from participants that the testing environment is unfamiliar and difficult to give their best effort. Most protocols have strict dietary guidelines, pre-exercise requirements and unfamiliar performance protocols. Elite athletes may complain that these unfamiliar protocols disrupt their normal prerace and race routines. Building a more familiar protocol without sacrificing reliability of results may allow experienced athletes to improve perception of confidence between trials (Paton and Hopkins 2006).

The primary purpose of the present study was to compare the effects of low and moderate doses of caffeine given in a carbohydrate-electrolyte solution (CES) late in exercise on TT cycling performance. We hypothesized that both doses of caffeine would improve TT performance but were not clear whether the moderate dose would be more beneficial than the 
low dose. We also utilized a testing protocol designed to improve familiarly, perception of confidence and built a more comfortable testing environment for the participants.

\section{Materials and methods}

\section{Subjects}

Fifteen $(11 \mathrm{M}, 4 \mathrm{~F})$ competitive cyclists (2-16 yr experience) volunteered for the study. Subject characteristics can be found in Table 2. Only one subject was a habitual caffeine user $(\geq$ $50 \mathrm{mg} \cdot$ day $\left.^{-1}\right)$. Female participants were taking oral contraceptives for 12 months or longer and testing was not standardized based on phases of the menstrual cycle. Subjects were fully informed of the purpose of the study and of potential risks before giving written and oral consent. This study was approved by the Research Ethics Committee at the University of Guelph.

\section{Study design}

Subjects visited the laboratory on six occasions. During the first visit, they performed an incremental cycling (Lode Excalibur, Quinton Instrument, Netherlands) test to exhaustion to determine peak oxygen consumption ( $\mathrm{VO}_{2}$ peak). Heart rate $(\mathrm{HR})$ and expired respiratory gases $\left(\mathrm{VO}_{2}, \mathrm{VCO}_{2}\right)$ were analyzed with a metabolic cart (Sensormedic, Vmax 229, Yorba Linda, CA). The remaining five trials consisted of one complete practice trial and four experimental trials.

\section{Pre-experimental procedures}

Practice and experimental trials consisted of a 120 min cycling challenge followed by a time trial to completion test (TT) in which subjects completed $6 \mathrm{~kJ}$ of work $\cdot \mathrm{kg} \mathrm{bm}^{-1}$ as quickly as possible (Figure 1). Subjects supplied their own pedals and saddle for each trial. Trials began 
with subjects cycling at $\sim 30-40 \% \mathrm{VO}_{2}$ peak for $5 \mathrm{~min}$. The remainder of the challenge consisted of steady state cycling at $\sim 60 \% \mathrm{VO}_{2}$ peak for 120 min with five interspersed simulated hill climbs (120 s each, $\sim 82 \% \mathrm{VO}_{2}$ peak) that were each followed by a simulated descent (50 W for $40 \mathrm{~s}$ ). Immediately following the 120 min cycling challenge, the Lode ergometer was set to an rpm dependent mode (linear mode) for the TT. Resistance was set to $\sim 80 \%$ of cyclist's peak power output for their respective average cadence during the 120 min challenge. During the TT, subjects only received information on total work completed $(\mathrm{kJ})$ and were blinded from all other information. HR and power output were recorded at $100 \mathrm{~kJ}$ increments throughout the TT.

\section{Experimental trials}

Participants completed four double-blinded randomized experimental trials consisting of the 120 min cycling challenge and TT stated above. No results were calculated or released until all the subjects had completed the study. Subjects were tested by the same person for each trial. To further encourage participants to give an all-out effort throughout the TT, bonus compensation was given to the fastest three TT's for each treatment. Participants could win a maximum of two awards.

Subjects arrived to the laboratory at the same time of day for all trials and completed one trial a week. Meals consumed $24 \mathrm{hr}$ prior to the trials were selected individually by subjects, were based on each cyclist's preferred pre-race routine, and were approved by the investigator to include balanced carbohydrate (50-70\%), protein (15-30\%), and fat (10-30\%) content. Participants repeated their individuated exercise tapering routine that they would carry out the day before a competitive cycling event. Participants either cycled at a low to moderate intensity ( $\sim 30-60 \mathrm{~min})$ or abstained from exercise the day before trials. To maintain familiarity, the single 
coffee drinker consumed their typical coffee intake prior to the trials. Diet and exercise logs were not recorded.

The laboratory environment was between $19-22{ }^{\circ} \mathrm{C}$ and $20-30 \%$ relative humidity. Upon arrival to the laboratory, a Teflon catheter was inserted into an antecubital vein for blood sampling and the catheter was kept patent by flushing with $0.9 \%$ saline. Venous blood samples were taken immediately prior to exercise and throughout exercise at 35, 55, 75, 120 min and when $85 \%$ of the TT was completed. Respiratory gases were collected between $13-17,33-37,53-$ 57 and 93-97 min of exercise. Heart rate was recorded throughout exercise and immediately upon completion of each hill climb. Body weight and urine were collected prior to and following exercise. Subjects towelled dry after trials for body weight measurements and urine was collected to analyze urinary specific gravity (USG) (Atago, Pocket Refractometer, Japan).

A CES containing $60 \mathrm{~g} \cdot 1^{-1} \mathrm{CHO}, 18 \mathrm{mEq} \cdot 1^{-1}$ sodium, $11 \mathrm{mEq} \cdot 1^{-1}$ chloride and $3 \mathrm{mEq} \cdot$ $1^{-1}$ potassium was given in a $3.0 \mathrm{ml} \cdot \mathrm{kg} \mathrm{bm}^{-1}$ bolus immediately prior to exercise and during exercise at 20, 40 and $60 \mathrm{~min}$. At $80 \mathrm{~min}$, subjects were given a $5.1 \mathrm{ml} \cdot \mathrm{kg} \mathrm{bm}^{-1} \mathrm{CES}$ with either, no caffeine $(\mathrm{PL}), 100 \mathrm{mg}$ caffeine $\left(1.5 \pm 0.1 \mathrm{mg} \cdot \mathrm{kg} \mathrm{bm}^{-1}\right)(\mathrm{CAF} 1)$, or $200 \mathrm{mg}$ caffeine $(2.9 \pm 0.1$ $\left.\mathrm{mg} \cdot \mathrm{kg} \mathrm{bm}^{-1}\right)(\mathrm{CAF} 2)($ Figure 1). Subjects were asked to finish each drink within $5 \mathrm{~min}$. When subjects reached 100 and 120 min of cycling during the preliminary practice trial, subjects were given 15 min to ingest CES ad lib and this same volume was given for all experimental trials (100 min: $\left.4.0 \pm 0.6 \mathrm{ml} \cdot \mathrm{kg} \mathrm{bm}^{-1}, 120 \mathrm{~min}: 2.9 \pm 0.6 \mathrm{ml} \cdot \mathrm{kg} \mathrm{bm}^{-1}\right)$.

A randomized fourth trial was completed, repeating either the PL, CAF1 or CAF2 treatment. With 15 subjects, 5 repeated the PL trial, 5 repeated the CAF1 trial, and 5 repeated the CAF2 trial. Following each trial subjects completed a post-trial questionnaire to distinguish if 
they thought caffeine was in the treatment they had received, and if so what cues led them to believe this.

\section{Blood measurements}

Venous blood was collected in sodium-heparin tubes. A portion of the pre-trial ( $0 \mathrm{~min})$ and final collection (during the TT) were used to measure hematocrit in triplicate. A portion (1.5 $\mathrm{ml}$ ) was added to $30 \mu \mathrm{l}$ of EGTA and reduced glutathione, centrifuged (10,000 x g for $3 \mathrm{~min})$ and the supernatant was analyzed for epinephrine using an enzymatic immunoassay (Labor Diagnostika Nord, Nordhorn, Germany). A second portion (200 $\mu \mathrm{l})$ was added to $800 \mu \mathrm{l}$ of $0.6 \mathrm{M}$ perchloric acid, centrifuged and the supernatant was analyzed for blood glucose and lactate using fluorometric techniques (Bergmeyer 1974). A third portion (1.5 ml) was centrifuged and the plasma was analyzed for free fatty acids using an enzymatic colorimetric technique (Wako NEFA C test kit, Wako Chemicals, Richmond, VA). A fourth portion was allowed to clot for 30 min, then centrifuged and the serum was transferred and frozen for analysis of caffeine concentrations on an Agilent Technologies Model 1100 HPLC (Palo Alto, CA) equipped with an ultraviolet detector set at $280 \mathrm{~nm}$.

\section{Statistics}

All data are presented as means \pm SE. Repeated TT's and pre vs. post trial body weight, hematocrit and USG data were analyzed using a paired t-test. All other data were analyzed by repeated measures ANOVA (time x treatment $\&$ time $\mathrm{x}$ trials) to determine significant differences during the trials and between treatments and trials. Specific differences were identified using a student Newman-Keuls post hoc test. Statistical significance was accepted at a level of $\mathrm{p}<0.05$. 


\section{Results}

\section{Descriptive Results}

Subjects arrived to the laboratory for each trial with a similar body mass $(70.8 \pm 2.9 \mathrm{~kg})$, USG $(1.013 \pm 0.002)$ and hematocrit $(46 \pm 1 \%)$. Subjects ingested $1792 \pm 68 \mathrm{ml}$ of CES and 337 $\pm 21 \mathrm{ml}$ of $0.9 \%$ saline was intravenously infused throughout each trial. During the TT hematocrit increased significantly to $49 \pm 1 \%$. Following the trials, body mass $(70.3 \pm 2.5 \mathrm{~kg})$ and USG $(1.017 \pm 0.002)$ were unchanged.

\section{Serum caffeine}

Caffeine concentrations were significantly elevated at 120 min during CAF1 $(14.9 \pm 2.6$ $\left.\mu \mathrm{mol} \cdot 1^{-1}\right)$ and to a greater extent during CAF2 $\left(24.9 \pm 3.2 \mu \mathrm{mol} \cdot 1^{-1}\right)$, but were negligible and unchanged during PL. Caffeine concentrations remained elevated throughout the TT (CAF1:

$$
\left.13.8 \pm 2.9 \mu \mathrm{mol} \cdot 1^{-1}, \mathrm{CAF} 225.6 \pm 2.6 \mu \mathrm{mol} \cdot 1^{-1}\right)
$$

\section{Time trial}

The average power output during the first $20 \mathrm{~min}$ of the TT was $241 \pm 7 \mathrm{~W}$. The average HR throughout the TT was $175 \pm 2$ beats $\cdot \min ^{-1}$ (Figure 2$)$. The CAF2 TT (26:36 $\pm 0: 22$ min:sec) was completed significantly faster than both the CAF1 TT (27:36 \pm 0:32 min:sec) and PL TT (28:41 \pm 0:38 min:sec), or 3.6\% and 7.3\% respectively, while CAF1 was completed significantly quicker (3.8\%) than PL (Figure $3 \&$ Table 1). The average difference between the two repeated TT's was low at 0:40 \pm 0:10 min:sec or 2.4\%. The first of the repeated TT's was completed with an average time of 27:19 \pm 0:30 min:sec and the repeated TT was completed 
with an average time of 27:30 $\pm 0: 35$ min:sec. There was no statistical difference between the repeated trials $(\mathrm{p}=0.803)$. Individual results are also presented in Figure 3.

\section{0 min cycling challenge}

The average power output during the steady state ride was $194 \pm 10 \mathrm{~W}$ and $285 \pm 14 \mathrm{~W}$ during the simulated hill climbs. This equated to $59 \%$ and $82 \%$ of $\mathrm{VO}_{2}$ peak respectively. $\mathrm{HR}$ was $147 \pm 7$ beats $\cdot \min ^{-1}$ during the steady state challenge, increased to $169 \pm 3$ beats $\cdot \min ^{-1}$ during hill climbs, and was not different between trials (Figure 4). There was no difference in respiratory measurements between trials, but there was an effect of time as $\mathrm{VO}_{2}$ was significantly higher at 95 min of exercise (Figure 5).

Blood glucose, plasma FFA, plasma epinephrine and blood lactate were not different between trials. Plasma FFA concentration was significantly higher following 120 min of exercise compared to rest. Plasma epinephrine significantly increased throughout exercise (Figure 6). Blood lactate rose $(\mathrm{p}<0.05)$ as exercise commenced, remained constant through completion of the 120 min ride, and increased further $(\mathrm{p}<0.05)$ following all treatments during the TT (Figure 6).

The post-trial questionnaire $(n=60)$ revealed that one subject correctly identified the placebo through a perception of being less energetic compared to the other trials. Fifteen of the caffeine trials (out of 40$)$ were correctly identified $(\mathrm{CAF} 1=7, \mathrm{CAF} 2=8)$ through a feeling of added "energy" or through an odd "chemical" flavour in the drink. Five placebo trials and one caffeine trial were incorrectly identified, and the remaining 39 trials were unidentifiable. 


\section{Discussion}

The current study examined the effects of low $\left(1.5 \mathrm{mg} \cdot \mathrm{kg} \mathrm{bm}^{-1}\right)$ and moderate $(2.9 \mathrm{mg} \cdot$ $\mathrm{kg} \mathrm{bm}^{-1}$ ) doses of caffeine delivered late in exercise on cycling TT performance. TT performances were enhanced by $3.6 \%$ following ingestion of the low dose of caffeine (100 $\mathrm{mg})$ and by $7.3 \%$ with the moderate dose of caffeine $(200 \mathrm{mg})$. In addition, a distinct ergogenic effect was observed between the two caffeine doses.

Three observations can be made from the current comparisons between low and moderate doses of caffeine as an ergogenic aid (Table 1); i) Increasing caffeine intake from a low $(<2.5$ $\left.\mathrm{mg} \cdot \mathrm{kg} \mathrm{bm}^{-1}\right)$ to a moderate dose $\left(\sim 3-6 \mathrm{mg} \cdot \mathrm{kg} \mathrm{bm}^{-1}\right)$ can increase the ergogenic effect when caffeine is ingested just prior $(<60 \mathrm{~min})$ to the endurance performances, ii) The timing of intake may significantly affect the efficacy of caffeine on endurance performance, iii) Mixed results between studies may suggest inter-individual differences in the optimal timing and minimal dose required to maximize performance benefits from caffeine during endurance performance.

Studies have not revealed an added ergogenic benefit from high doses of caffeine $(>6$ MG) compared to a moderate dose (Lindinger et al. 1993; Graham and Spriet 1995; Bruce et al. 2000; Anderson et al. 2000), however results from the current study and from Kovacs et al. (1998) revealed that a moderate dose $\left(\sim 3-6 \mathrm{mg} \cdot \mathrm{kg} \mathrm{bm}^{-1}\right)$ improved cycling performances to a greater extent than a low dose of caffeine $\left(<2.5 \mathrm{mg} \cdot \mathrm{kg} \mathrm{bm}^{-1}\right)$. These observations suggest that a moderate dose may be the minimal concentration required to maximize the ergogenic effects of caffeine and that contrasting studies that have not observed a difference between a low and moderate dose (Cox et al. 2002; Desbrow et al 2009; Jenkins et al. 2008) may have given the initial bolus of caffeine too long before the TT. An eloquent review of the literature by Burke 
(2008) suggested that "if a dose-response exists, there is a plateau at $\sim 3 \mathrm{mg} \cdot \mathrm{kg} \mathrm{bm}^{-1}$ ". However the timing of intake during exercise may also be of significant importance.

Results from comparable studies in Table 1 may suggest that when caffeine was ingested within 60 min of the TT, clear differences were apparent between a low and moderate dose (Table 1). When caffeine was initially ingested $80-180$ before the TT there was no difference between the low and moderate concentration on performance (Desbrow et al 2009; Jenkins et al. 2008) even though throughout the TT blood caffeine levels remained elevated and were higher in the moderate dose compared to the low dose. While data is limited, this may suggest caffeine initially ingested $\sim 40-60$ min before performances will yield the maximal ergogenic benefit. It is plausible that the sensitivity to caffeine on central and/or peripheral mechanisms (Lopes et al. 1983; Lindinger et al. 1993; Tarnopolsky and Cupido 2000; Davis et al. 2003; O'Conner et al. 2004; Motl et al. 2006) of action dull over time even though plasma caffeine concentrations stay elevated. Interestingly Cox et al. (2002) observed that a very low dose $\left(\sim 1.3 \mathrm{mg} \cdot \mathrm{kg} \mathrm{bm}^{-1}\right)$ ingested 20-40 min before the TT improved performance to a similar extent to a high moderate dose $\left(6 \mathrm{mg} \cdot \mathrm{kg} \mathrm{bm}^{-1}\right)$ initially ingested 120 or $180 \mathrm{~min}$ before the TT.

The current study observed a clear enhanced ergogenic benefit with a moderate dose compared to a low dose. However there could be inter-individual differences in the efficacy of caffeine on endurance performance. Previous evidence (Bell and McLellan 2002; Kalow 1985; Conway et al. 2003; Temple et al. 2014; Paton et al. 2015) suggests that individuals have varied responses to caffeine. While the present study yielded a statistical advantage with a moderate (CAF2) vs. low (CAF1) dose, six subjects completed CAF1 and CAF2 within 30 seconds of each other (Figure 3). A possible explanation may include slight differences in individual phenotypic responses to caffeine (Chesley et al. 1998; Crews et al. 2001; Yang et al. 2010) and may be large 
enough in some circumstances to significantly impact ergogenic benefits. A persuasive review of caffeine's effect on pairs of twins suggested that genomic variation may account for significant differences in caffeine's direct effect on the body (Yang et al. 2010). Based on these initial observations, athletes planning to chronically consume caffeine to improve performances may have to experiment with varied low and moderate doses of caffeine to determine the minimal optimal concentration. With known side effects (Gilliland and Bullock 1983; Silverman et al. 1992; James 1998; Fredholm et al. 1999; Salinero et al. 2014) and increased use by adolescence athletes (Seifert et al. 2011) it may prudent to be cautious when prescribing dosage.

The current study protocol took a unique approach to the standard 120 min steady state challenge and pre-trial preparation. The 120 min cycling challenge included simulated hill climbs and descents typically observed in road races. While there is currently limited evidence, the varied work rates may have impacted their TT performance (Fonda et al. 2011; Thomas et al. 2013; Stebbins et al. 2014) and limited monotony. Varied work rates and cadences allowed riders to make position adjustments in the saddle altering biomechanical movement and muscle group contributions more similar to a road race (Fonda et al. 2011). During descents, freewheeling and backpedaling added familiarity and may have limited the perception of muscle fatigue.

In addition to changes in the cycling protocol, participants chose their preferred pre-race meals and there was some individualization of total fluid intake during the trial (at 100 and 120 min of exercise). Competitors often eat meals that have previously preceded successful performances. Preferred diets may include foods that limit gastrointestinal (GI) discomfort, are better absorbed, supplement dietary deficiencies, and provide a feeling of comfort prior to an event (Maughan 2001). These food qualities are not uniform between individuals and the optimal diet as well as fluid needs likely vary between athletes. 
In summary both a low $\left(1.5 \mathrm{mg} \cdot \mathrm{kg} \mathrm{bm}^{-1}, 100 \mathrm{mg}\right)$ and moderate $\left(2.9 \mathrm{mg} \cdot \mathrm{kg} \mathrm{bm}^{-1}, 200\right.$ $\mathrm{mg}$ ) dose of caffeine ingested late in exercise and 40 min prior to a TT improved performance. In addition, the moderate dose improved performance to a greater extent than the low dose. Results suggest that a moderate dose of caffeine $\left(\sim 3 \mathrm{mg} \cdot \mathrm{kg} \mathrm{bm}^{-1}\right)$, given during a prolonged steady state exercise and $\sim 40$ min prior to a TT, is more ergogenic than a low dose in trained cyclist.

\section{Acknowledgements}

This study was supported by a research grant to LS from the Natural Science and Engineering Council of Canada.

\section{Disclosures}

No conflict of interests are reported by the authors. 


\section{References}

Anderson, M.E., Bruce, C.B., Fraser, S.F., Stepto, N.K., Klein, R., Hopkins, W.G., and Hawley, J.A. 2000. Improved 2000-meter rowing performance in competitive oarswomen after caffeine ingestion. Int. J. Sport Nutr. Exerc. Metab. 10(4): 464-475.

Bell, D.G., and McLellan, T.M. 2002. Exercise endurance 1, 3, and $6 \mathrm{~h}$ after caffeine ingestion in users and nonusers. J. Appl. Physiol. 93(4): 1227-1234.

Bergmeyer, H.U. 1974. Methods in Enzymatic Analysis. Academic, New York.

Bridge, C.A., and Jones, M.A. 2006. The effect of caffeine ingestion on $8 \mathrm{~km}$ run performance in a field setting. J. Sports Sci. 24: 433-449. doi: 10.1080/02640410500231496.

Burke, L.M. 2008. Caffeine and sports performance. Appl. Physiol. Nutr. Metab. 33(6): 13191334. doi: 10.1139/H08-130.

Bruce, C.B., Anderson, M.E., Fraser, S.F., Stepto, N.K., Klein, R., Hopkins, W.G., and Hawley, J.A. 2000. Enhancement of 2000-m rowing performance after caffeine ingestion. Med. Sci. Sports Exerc. 32(11): 1958-1963.

Chesley, A., Howlett, R.A., Heigenhauser, G.J., Hultman, E., and Spriet, L.L. 1998. Regulation of muscle glycogenolytic flux during intense aerobic exercise after caffeine ingestion. Am. J. Physiol. 275(2 Pt. 2): R596-603.

Conway, K.J., Orr, R., and Stannard, S.R. 2003. Effect of a divided dose of endurance cycling performance, postexercise urinary caffeine concentration and plasma paraxanthine. J. Appl. Physiol. 94(4): 1557-1562.

Cox, G.R., Desbrow, B., Montgomery, P.G., Anderson, M.E., Bruce, C.R., Macrides, T.A., Martin D.T., Moquin, A., Roberts, A., Hawley, J.A., and Burke, L.M. 2002. Effect of different 
protocols of caffeine intake on metabolism and endurance performance. J. Appl. Physiol. 93(3): 990-999.

Crews, H.M., Olivier, L., and Wilson, A. 2001. Urinary biomarkers for assessing dietary exposure to caffeine. Food Addit. Contam. 18(12): 1075-187.

Davis, J.M., Zhao, Z., Stock, H.S., Mehl, K.A., Buggy, J., and Hand, G.A. 2003. Central nervous system effects of caffeine and adenosine on fatigue. Am. J. Physiol. 284(2): R399-R404.

Desbrow, B., and Leveritt, M. 2006. Awareness and use of caffeine by athletes competing at the 2005 Ironman Triathlon World Championships. Int. J. Sport Nutr. Exerc. Metab. 16(5): 545-558. Desbrow, B., and Leveritt, M. 2007. Well-trained endurance athletes' knowledge, insight, and experience of caffeine use. Int. J. Sport Nutr. Exerc. Metab. 17(4): 328-339.

Desbrow, B., Barrett, C.M., Minahan, C.L., Grant, G.D., and Leveritt, M.D. 2009. Caffeine, Cycling Performance, and Exogenous CHO Oxidation: A Dose-Response Study. Med. Sci. Sports Exerc. 41(9): 1744-1751. doi: 10.1249/MSS.0b013e3181a16cf7.

Doherty, M., and Smith, P.M. 2004. Effects of caffeine ingestion on exercise testing: a metaanalysis. Int. J. Sport Nutr. Exerc. Metab. 14(6): 626-646.

Fonda, B., Panjian, A., Markovic, G., and Sarabon, N. 2011. Adjusted saddle position counteracts the modified muscle activation patterns during uphill cycling. J. Electromyogr. Kinesiol. 21(5): 854-860. doi: 10.1016/j.jelekin.2011.05.010.

Fredholm, B.B., Battig, K., Holmen, J., Nehlig, A., and Zvartau, E.E. 1999. Actions of caffeine in the brain with special reference to factors that contribute to its widespread use. Pharmacol. Rev. 51(1): 83-133.

Gilliland, K., and Bullock, W. 1983. Caffeine: a potential drug of abuse. Adv. Alcoh. Subst. 3(12): 53-73. 
Graham, T.E. 2001. Caffeine and exercise: metabolism, endurance and performance. Sports Med. 31(11): 785-807.

Graham, T.E., and Spriet, L.L. 1995. Metabolic, catecholamine and exercise performance responses to varying doses of caffeine. J. Appl. Physiol. 78(3): 867-874.

Ivy, J.L., Costill, D.L., Fink, W.J., and Lower, R.W. 1979. Influence of caffeine and carbohydrate feedings on endurance performance. Med. Sci. Sports Exerc. 11(1): 6-11.

James, J.E. 1998. Acute and chronic effects of caffeine on performance, mood, headache, and sleep. Neuropsychobiology. 38(1): 32-41.

Jenkins, N.T., Trilk, J.L., Singhal, A., O’Conner, P.J., and Cureton, K.J. 2008. Ergogenic effects of low doses of caffeine on cycling performance. Int. J. Sport Nutr. Exerc. Metab. 18(3): 328342.

Kalow, W. 1985. Variability of caffeine metabolism in humans. Arzneimittelforschung. 35(1A): 319-324.

Kovacs, E.M., Stegen, J., and Brouns, F. 1998. Effect of caffeinated drinks on substrate metabolism, caffeine excretion, and performance. J. Appl. Physiol. 85(2): 709-715.

Lindinger, M.I., Graham, T.E., and Spriet, L.L. 1993. Caffeine attenuates the exercise-induced increase in plasma potassium in humans. J. Appl. Physiol. 74(3): 1149-1155.

Lopes, J.M., Aubier, M., Jardim, J., Aranda, J.V., and Macklem, P.T. 1983. Effect of caffeine on skeletal muscle function before and after fatigue. J. Appl. Physiol. Respir. Environ. Exerc. Physiol. 54(5): 1303-1305.

Maughan, R. 2001. Food and fluid intake during exercise. Can. J. Appl. Physiol. 26: S71-S78. Motl, R.W., O'Connor, P.J., Tubandt, L., Puetz, T., and Ely, M.R. 2006. Effect of caffeine on leg muscle pain during cycling exercise among females. Med. Sci. Sports Exerc. 38(3): 598-604. 
O'Connor, P.J., Motl, R.W., Broglio, S.P., and Ely, M.R. 2004. Dose-dependent effect of caffeine on reducing leg muscle pain during cycling exercise is unrelated to systolic blood pressure. Pain. 109(3): 291-298.

Paton, C.D., and Hopkins, W.G. 2006. Variation in performance of elite cyclists from race to race. Eur. J. Sport Sci. 6(1): 25-31.

Paton, C., Costa, V., and Guglielmo, L. 2015. Effects of caffeine chewing gum on race performance and physiology in male and female cyclists. J. Sports Sci. 33(10): 1076-1083. doi: 10.1080/02640414.2014.984752.

Salinero, J.J., Lara, B., Abian-Vicen, J., Gonzalez-Millan, C., Areces, F., Gallo-Salazar, C., Ruiz-Vicente, D., and Del Coso, J. 2014. The use of energy drinks in sport: perceived ergogenicity and side effects in male and female athletes. Br. J. Nutr. 112(9): 1494-1502. doi: $10.1017 / \mathrm{S} 0007114514002189$.

Scott, A.T., O'Leary, T., Walker, S., and Owen, R. 2015. Improvement of 2000-m rowing performance with caffeinated carbohydrate-gel ingestion. Int. J. Sports Physiol. Perform. 10(4): 464-468. doi: 10.1123/ijspp.2014-0210.

Seifert, S.M., Schaechter, J.L., Hershorin, E.R., and Lipshultz, S.E. 2011. Health effects of energy drinks on children, adolescents, and young adults. Pediatrics. 127(3): 511-528. doi: 10.1542/peds.2009-3592.

Silverman, K., Evans, S.M., Strain, E.C., and Griffiths, R.R. 1992. Withdrawal syndrome after the double-blind cessation of caffeine consumption. N. Engl. J. Med. 327(16): 1109-1114.

Stebbins, C.L., Moore, J.L., and Casazza, G.A. 2014. Effects of cadence on aerobic capacity following a prolonged varied cycling trial. J. Sports Sci. Med. 13(1): 114-119. 
Tarnopolsky, M., and Cupido, C. 2000. Caffeine potentiates low frequency skeletal muscle force in habitual and nonhabitual caffeine consumers. J. Appl. Physiol. 89(5): 1719-1724.

Temple, J.L., Ziegler, A.M., Graczyk, A., Bendlin, A., Sion, T., and Vattana, K. 2014. Cardiovascular responses to caffeine by gender and pubertal stage. Pediatrics. 134(1): 112-119. doi: 10.1542/peds.2013-3962.

Thomas, K., Stone, M., St Clair Gibson, A., Thompson, K., Ansley, L. 2013. The effect of an even-pacing strategy on exercise tolerance in well-trained cyclists. Eur. J. Appl. Physiol. 113(12): 3001-3010. doi: 10.1007/s00421-013-2734-4.

Wiles, J.D., Bird, S.R., Hopkins, J., and Riley, M. 1992. Effect of caffeinated coffee on running speed, respiratory factors, blood lactate and perceived exertion during 1500-m treadmill running. Br. J. Sports Med. 26(2): 116-120.

Yang, A., Palmer, A.A., and de Wit, H. 2010. Genetics of caffeine consumption and responses to caffeine. Psychopharmacology. 211(3): 245-257. doi: 10.1007/s00213-010-1900-1. 
Table 1. Results from investigations that compared varied low to moderate doses of caffeine on endurance performance.

\begin{tabular}{|c|c|c|c|c|}
\hline Authors & $\begin{array}{l}\text { Caffeine dose } \\
\left(\mathrm{mg} \cdot \mathrm{kg} \mathrm{bm}^{-1}\right)\end{array}$ & Timing of caffeine intake & Cycling challenge & $\begin{array}{c}\text { TT Performance compared } \\
\text { to placebo }\end{array}$ \\
\hline \multirow[t]{2}{*}{ Kovacs et al. (1998) } & 2.1 & $60 \mathrm{~min}$ prior to $\mathrm{TT}$ & $\sim 60 \mathrm{~min} \mathrm{TT}$ & $\sim 1.8 \%$ improvement \\
\hline & 3.2 or 4.5 & $60 \mathrm{~min}$ prior to $\mathrm{TT}$ & $\sim 60 \mathrm{~min} \mathrm{TT}$ & $\sim 4.4 \%$ improvement $*$ \\
\hline \multirow[t]{3}{*}{ Cox et al. (2002) } & 6.0 & $180 \mathrm{~min}$ prior to $\mathrm{TT}$ & $120 \operatorname{min~SS}+7 \mathrm{~kJ} \cdot \mathrm{kg} \mathrm{bm}^{-1} \mathrm{TT}$ & $3.4 \%$ improvement \\
\hline & 6.0 & $\begin{array}{l}\text { throughout } 120 \mathrm{~min} \\
\text { prior to the } \mathrm{TT}\end{array}$ & $120 \operatorname{min~SS}+7 \mathrm{~kJ} \cdot \mathrm{kg} \mathrm{bm}^{-1} \mathrm{TT}$ & $3.1 \%$ improvement \\
\hline & $\sim 1.3$ & $20-40 \mathrm{~min}$ prior to $\mathrm{TT}$ & $120 \operatorname{min~SS}+7 \mathrm{~kJ} \cdot \mathrm{kg} \mathrm{bm}^{-1} \mathrm{TT}$ & $3.1 \%$ improvement \\
\hline \multirow[t]{2}{*}{ Jenkins et al. (2008) } & 1.0 & $\sim 80 \mathrm{~min}$ prior to $\mathrm{TT}$ & $\begin{array}{c}15 \min \mathrm{SS}+4 \text { min easy }+ \\
15 \min \mathrm{TT}\end{array}$ & no improvement \\
\hline & 2.0 or 3.0 & $\sim 80$ min prior to $\mathrm{TT}$ & $\begin{array}{c}15 \min \mathrm{SS}+4 \text { min easy }+ \\
15 \min \mathrm{TT}\end{array}$ & $3-4 \%$ improvement \\
\hline Desbrow et al. (2009) & 1.5 or 3.0 & $180 \mathrm{~min}$ prior to $\mathrm{TT}$ & $120 \min \mathrm{SS}+7 \mathrm{~kJ} \cdot \mathrm{kg} \mathrm{bm}^{-1} \mathrm{TT}$ & no improvement \\
\hline \multirow{2}{*}{$\begin{array}{l}\text { Talanian and Spriet } \\
\text { (current study) }\end{array}$} & 1.5 & $40 \mathrm{~min}$ prior to $\mathrm{TT}$ & $120 \mathrm{~min} \mathrm{SS}+6 \mathrm{~kJ} \cdot \mathrm{kg} \mathrm{bm}^{-1} \mathrm{TT}$ & $3.8 \%$ improvement \\
\hline & 2.9 & 40 min prior to $\mathrm{TT}$ & $120 \min \mathrm{SS}+6 \mathrm{~kJ} \cdot \mathrm{kg} \mathrm{bm}^{-1} \mathrm{TT}$ & $7.2 \%$ improvement $*$ \\
\hline
\end{tabular}

bm, body mass; SS, steady state; TT, time trial performance. * Significantly greater than the low dose $\left(<\sim 2 \mathrm{mg} \cdot \mathrm{kg} \mathrm{bm}^{-1}\right)$. 
Table 2. Subject characteristics.

\section{Age (yr) Weight (kg) $\quad$ VO$_{2}$ peak $\left(\mathrm{ml} \cdot \mathrm{min}^{-1} \cdot \mathrm{kg}^{-1}\right) \quad$ Peak Power $(W)$}

\begin{tabular}{lcccc}
\hline Subjects $(\mathrm{n}=15)$ & $22.5 \pm 0.9$ & $69.3 \pm 2.6$ & $64.6 \pm 1.9$ & $362 \pm 15.7$ \\
Males $(\mathrm{n}=11)$ & $22.6 \pm 1.1$ & $73.5 \pm 2.4$ & $66.6 \pm 2.0$ & $392 \pm 9.9$ \\
Females $(\mathrm{n}=4)$ & $22.3 \pm 2.0$ & $57.5 \pm 1.7$ & $58.8 \pm 3.8$ & $280 \pm 18.4$ \\
\hline
\end{tabular}

Values are means $\pm \mathrm{SE}$. 


\section{Figure captions}

Figure 1. $120 \mathrm{~min}$ cycling challenge plus $6 \mathrm{~kJ} \cdot \mathrm{kg} \mathrm{bm}^{-1}$ time trial. Values are means $\pm \mathrm{SE} . \mathrm{bm}$, body mass; CES, carbohydrate-electrolyte solution; TT, time trial; W, watts. $\uparrow, 3 \mathrm{ml} \cdot \mathrm{kg} \mathrm{bm}^{-1}$ of CES ingested. $\uparrow^{*}, 5 \mathrm{ml} \cdot \mathrm{kg} \mathrm{bm}^{-1} \mathrm{CES}$ with or without caffeine. $\uparrow^{* *}$, average CES ingested was 4 $\mathrm{ml} \cdot \mathrm{kg} \mathrm{bm}^{-1} \cdot \uparrow^{* * *}$, average CES ingested was $3 \mathrm{ml} \cdot \mathrm{kg} \mathrm{bm}^{-1}$.

Figure 2. Average heart rate and power output throughout the time trial for subjects that completed a minimum of $400 \mathrm{~kJ}$. Values are means $\pm \mathrm{SE}, \mathrm{n}=12$. PL, placebo; CAF1, $100 \mathrm{mg}$ caffeine; CAF2, $200 \mathrm{mg}$ caffeine. * Significantly different than $100 \mathrm{~kJ}(\mathrm{p}<0.05)$.

Figure 3. Time trial performances. Bars represent mean data for each treatment. Lines represent individual time trial performances across each treatment. $\mathrm{n}=15$. PL, placebo; CAF1, $100 \mathrm{mg}$ caffeine; CAF2, $200 \mathrm{mg}$ caffeine. * Significantly faster than PL $(\mathrm{p}<0.05) . \dagger$ Significantly faster than CAF1 $(\mathrm{p}<0.05)$.

Figure 4. Heart rate measurements throughout the $120 \mathrm{~min}$ cycling challenge. Values are means $\pm \mathrm{SE}, \mathrm{n}=15$.

Figure 5. Respiratory measurements throughout the 120 min cycling challenge. Values are means $\pm \mathrm{SE}, \mathrm{n}=15 . \mathrm{VO}_{2}$, oxygen consumption; RER, respiratory exchange ratio. * Significantly different than 15 min of exercise $(p<0.05)$.

Figure 6. Plasma epinephrine and blood lactate throughout the cycling trial. Values are means \pm $\mathrm{SE}, \mathrm{n}=15 . *$ Significantly greater than rest $(\mathrm{p}<0.05) . \dagger$ Significantly greater than 120 min. 


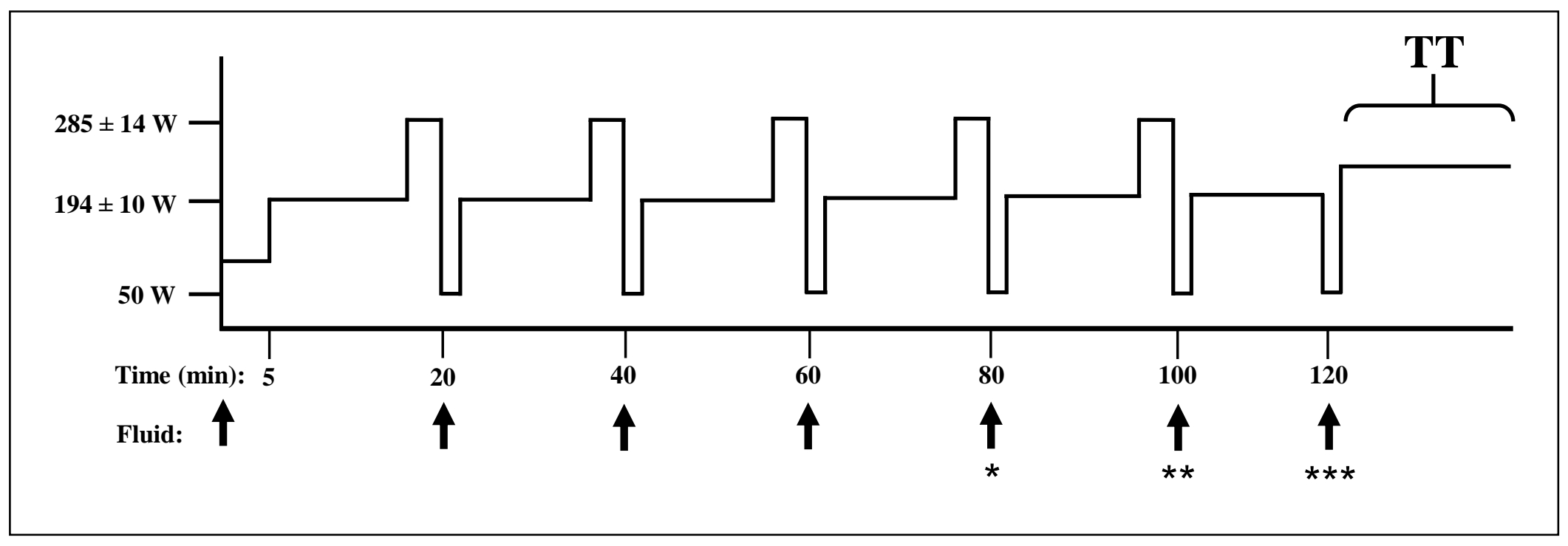



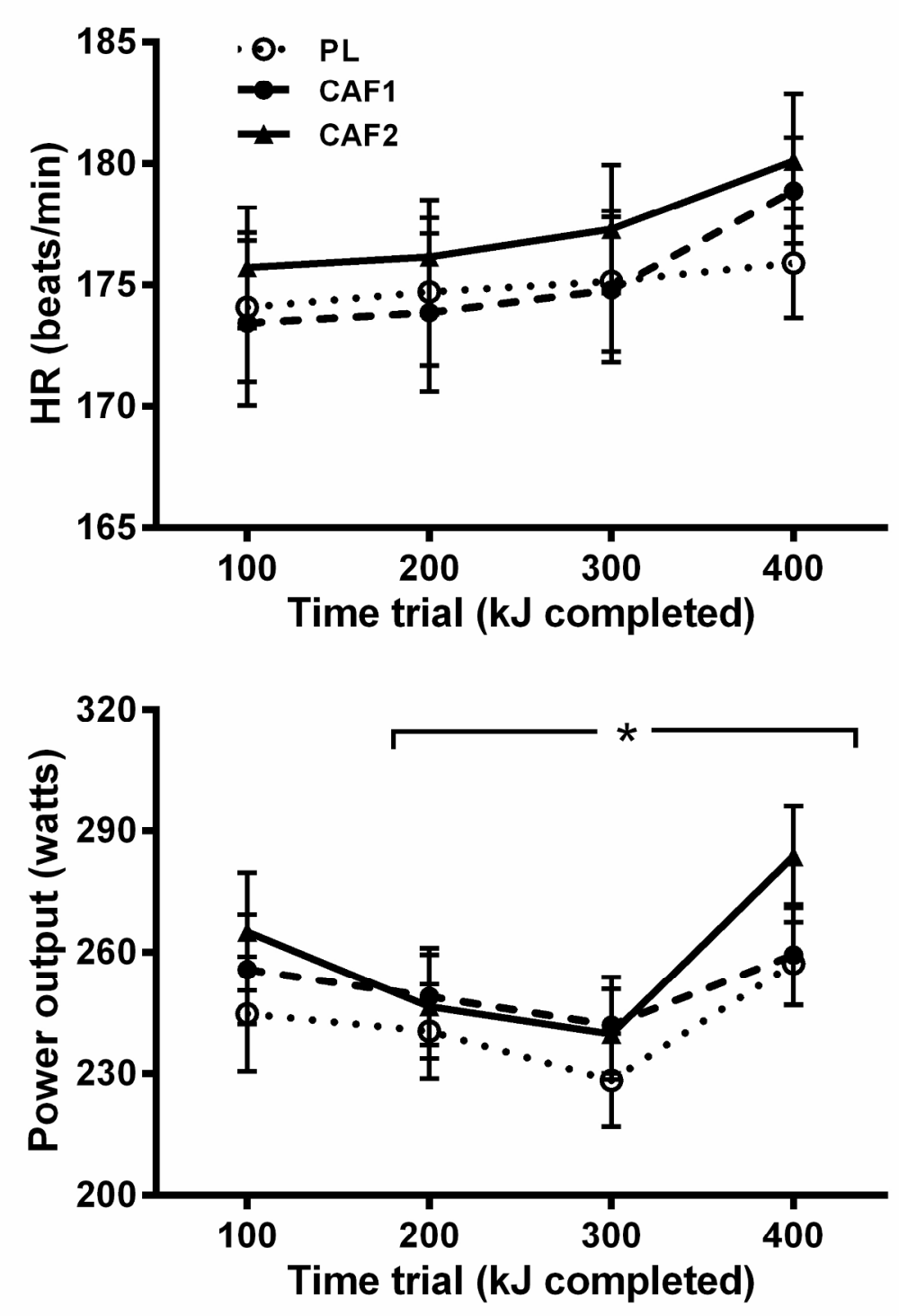

Figure 2. Average heart rate and power output throughout the time trial for subjects that completed a minimum of $400 \mathrm{~kJ}$. Values are means $\pm \mathrm{SE}, \mathrm{n}=12$. PL, placebo; CAF1, $100 \mathrm{mg}$ caffeine; CAF2, $200 \mathrm{mg}$ caffeine. * Significantly different than $100 \mathrm{~kJ}(\mathrm{p}<0.05)$.

$186 \times 249 \mathrm{~mm}(300 \times 300 \mathrm{DPI})$ 


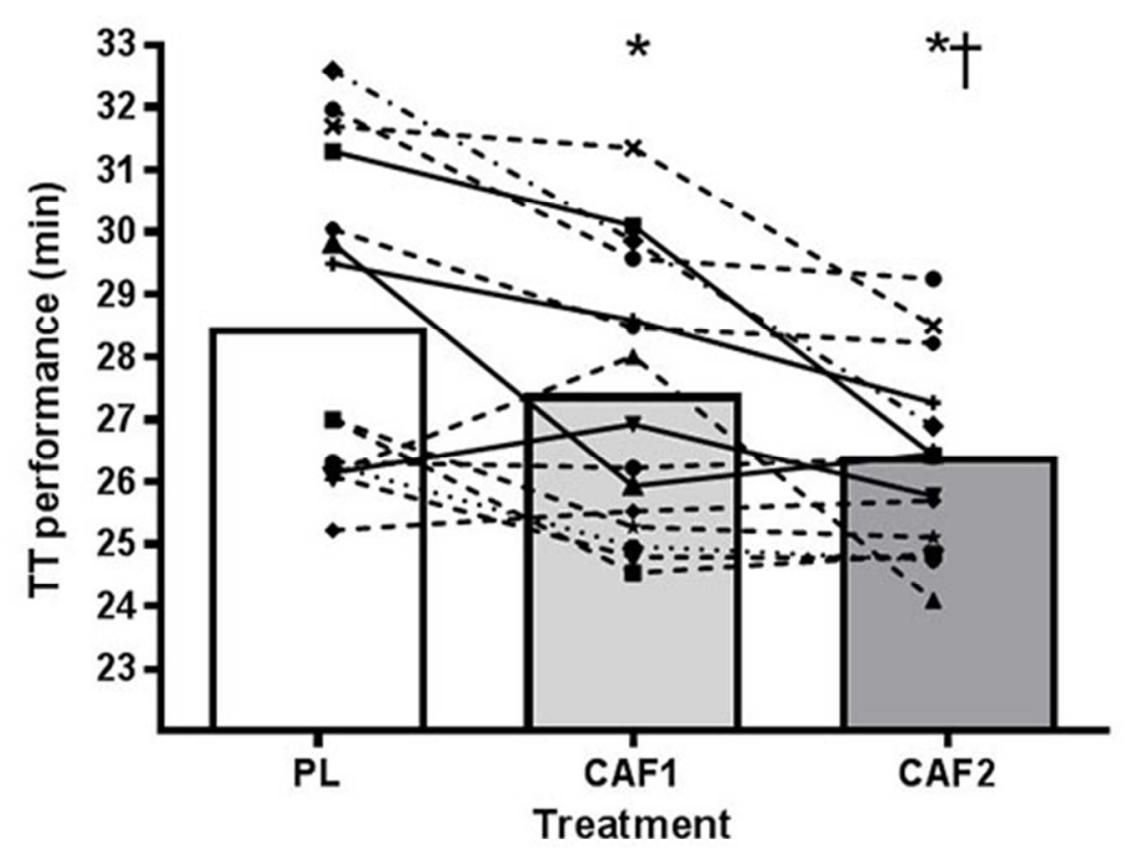

Figure 3. Time trial performances. Bars represent mean data for each treatment. Lines represent individual time trial performances across each treatment. $n=15$. PL, placebo; CAF1, $100 \mathrm{mg}$ caffeine; CAF2, $200 \mathrm{mg}$ caffeine. * Significantly faster than PL $(p<0.05)$. + Significantly faster than CAF1 $(p<0.05)$. $50 \times 39 \mathrm{~mm}(300 \times 300 \mathrm{DPI})$ 


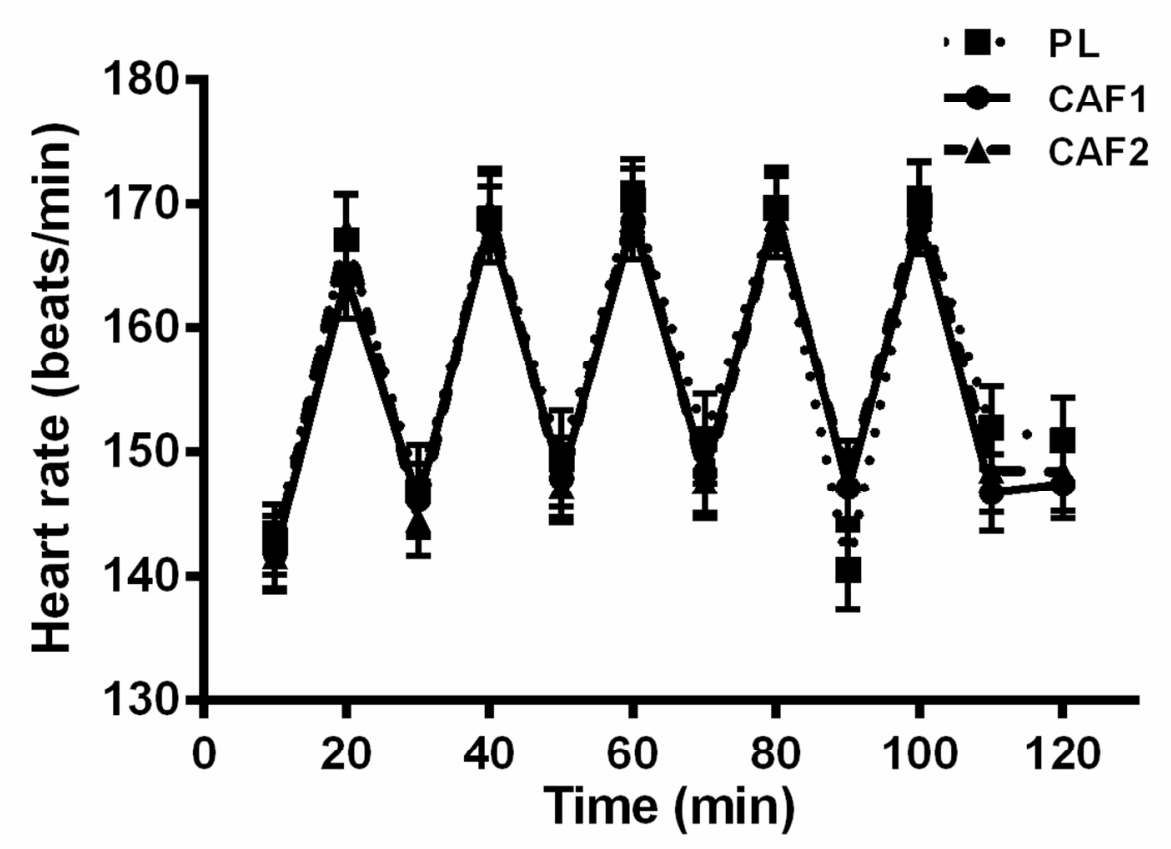

Figure 4. Heart rate measurements throughout the 120 min cycling challenge. Values are means $\pm S E, n=$ 15.

$106 \times 74 \mathrm{~mm}(300 \times 300$ DPI $)$ 

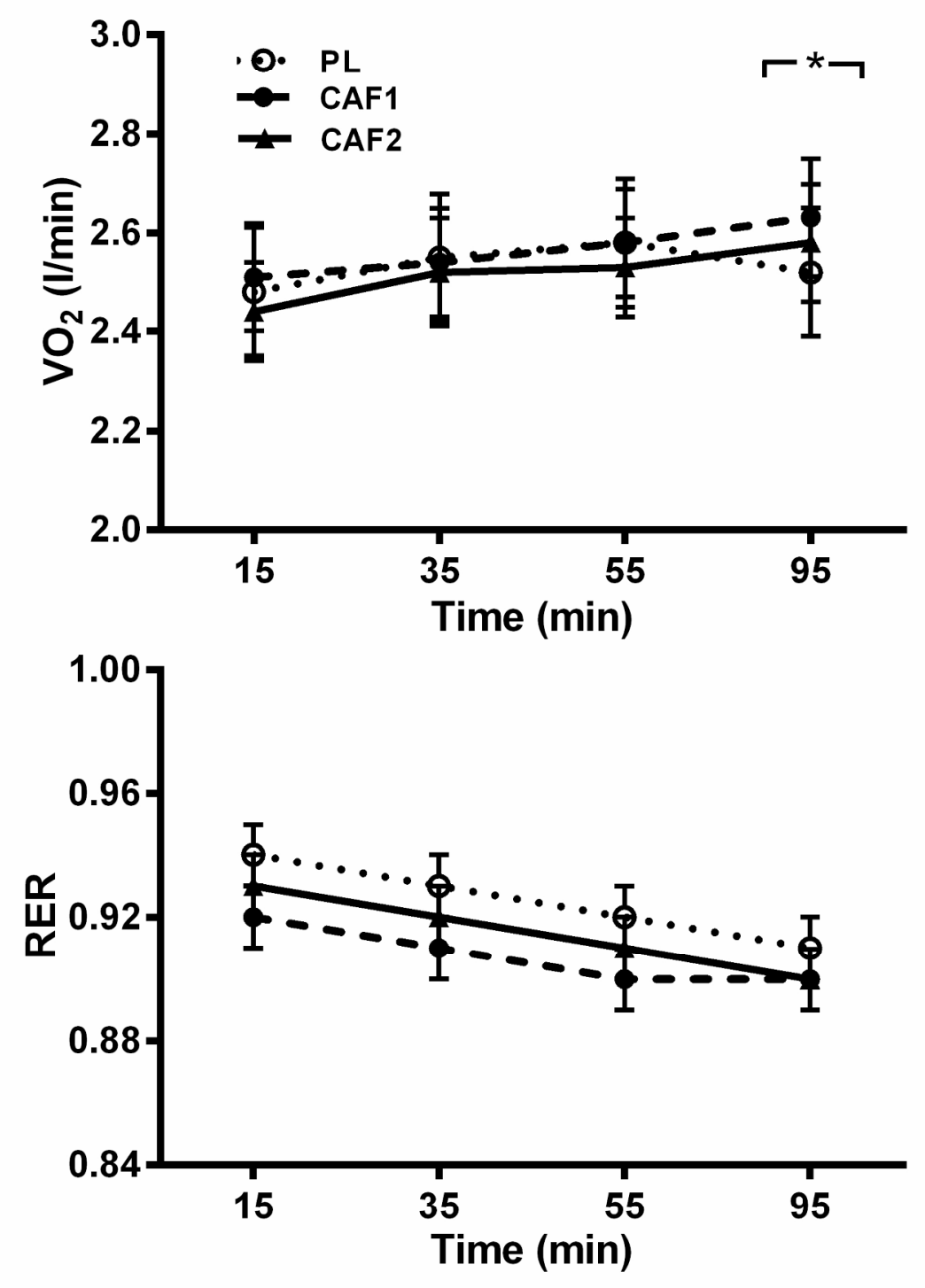

Figure 5. Respiratory measurements throughout the 120 min cycling challenge. Values are means $\pm S E, n$ $=15$. VO2, oxygen consumption; RER, respiratory exchange ratio. ${ }^{*}$ Significantly different than 15 min of exercise $(p<0.05)$. $187 \times 241 \mathrm{~mm}(300 \times 300$ DPI $)$ 

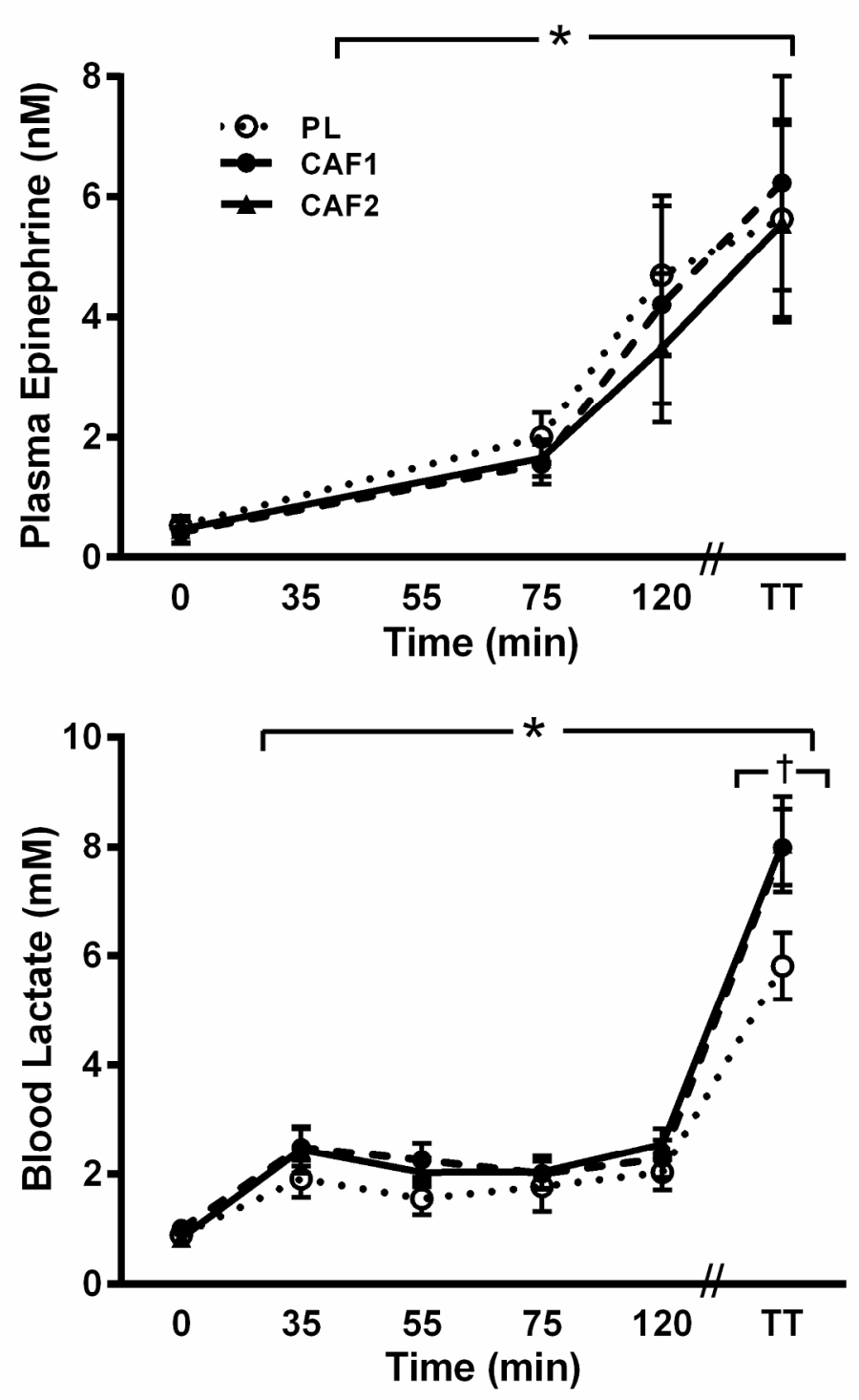

Figure 6. Plasma epinephrine and blood lactate throughout the cycling trial. Values are means $\pm \mathrm{SE}, \mathrm{n}=$ 15. * Significantly greater than rest $(p<0.05)$. + Significantly greater than $120 \mathrm{~min}$. $161 \times 236 \mathrm{~mm}(300 \times 300$ DPI) 